\title{
Miguel Torga: a paixão e a história poética da Ibéria
}

\section{Eugenio Brauner}

\begin{abstract}
Resumo: Na obra de Miguel Torga um dos temas mais recorrentes é o da pátria portuguesa - a terra lusa, seu povo e sua cultura; porém, no seu livro Poemas Ibéricos o poeta trásmontano transcende as fronteiras portuguesas para ver a Península Ibérica como uma terra só - ignorando, portanto, a rivalidade existente entre portugueses e espanhóis - e aborda a sua história através das suas viagens marítimas e heróis na tentativa de valorizar assim a auto-estima de um povo que vivia então sob os mandos de Salazar e Franco.
\end{abstract}

Palavras-chave: Poesia portuguesa; Miguel Torga; Península Ibérica; Ditadura militar

\begin{abstract}
One of the most recurrent themes in Miguel Torga's works is Portugal - its landscape, people and culture. However, in Torga's Poemas Ibéricos, the poet from Trás-Os-Montes goes beyond Portugal's boundaries to see the Iberian Peninsula as a whole consequently leaving aside the rivalry between Portugal and Spain - and approaches its history based on sea travels and heroes in an attempt to restore the self-esteem of a people that lived under Salazar's and Franco's dictatorships.
\end{abstract}

Keywords: Portuguese poetry; Miguel Torga; Iberian Peninsula; Dictatorship.

Nascido na pobre região de Trás-os-Montes, Miguel Torga foi um poeta que transgrediu as rivalidades regionais através da sua obra poética. Cantou nos seus versos Portugal e Espanha, países irmãos - no seu ponto de vista - por partilharem as mesmas terras secas da Península Ibérica.

Formado em medicina, Adolfo Correia da Rocha sempre foi um apaixonado pela Ibéria. Seu pseudônimo é a soma desta paixão: tornou-se Miguel e assim uniu-se a outros "miguéis" famosos - Miguel de Cervantes, Miguel de Molinos e Miguel de Unamuno; Torga surgiu a partir de uma erva daninha que vive nas encostas pedregosas da região trásmontana. Portanto, não existe um escritor mais ibérico que Miguel Torga, o qual dizia que a sua pátria cívica acabava em Barca de Alva, mas a sua pátria telúrica terminava apenas nos Pirineus:

É preciso reconhecer que, passados os Pirineus, o ar é mais leve, a terra é mais fecunda, a paisagem é mais doce. Mas eu prefiro o pesadelo, a pobreza e a agressividade do outro lado. [...] Há uma grandeza que se não mede em calorias e salamaleques. É coisa mais profunda e significativa... Ora essa grandeza tem-na a Espanha, faminta, esfarrapada, a arder em febre desde que nasceu (Torga, 1955; 126).

\footnotetext{
* Eugenio Brauner é estudante do curso de Letras da UFRGS e pesquisador da FAPERGS no projeto "A Contribuição do Conto para uma Concepção de Identidade nas Literaturas Latino-Americanas", realizado na mesma universidade.
} 
A Península Ibérica sempre fora vista com má vontade pelo restante da Europa considerada o exótico quintal do continente. José Saramago, no seu romance A Jangada de Pedra, narra a separação da Península do restante da Europa e o seu navegar pelo Atlântico. No trecho a seguir podemos ver como foi tratada a situação em uma das reuniões da Comunidade Econômica Européia que apenas insinuou que a "Península Ibérica se queria ir embora, então que fosse, o erro foi tê-la deixado entrar" (Saramago, 1988, p. 42). E com a ausência de estranhamento que o passar do tempo trouxe:

Os europeus, desde os máximos governantes aos cidadãos comuns, depressa se tinham acostumado, suspeita-se que com um inexpresso sentimento de alívio, à falta das terras extremas ocidentais, e se os novos mapas, rapidamente postos em circulação para actualização cultural do popular, ainda causavam à vista um certo desconforto, seria tão-somente por motivos de ordem estética (Saramago, 1988, p. 151- 152).

A literatura sempre esteve envolvida em questões de nacionalidade. Walter Scott, Alexandre Herculano e José de Alencar tiveram a preocupação de mostrar e, principalmente, valorizar os traços nacionais em algumas de suas obras. Eles tiveram a preocupação de unificar o país, mostrar o orgulho de pertencer a tal pátria e sua cultura, fundar uma unidade nacional, conforme afirma João Leal.

a identidade nacional repousaria sobre um conjunto de representações e rituais relacionados com o território e a história e sobre uma cultura cívica assente num conjunto de direitos e deveres comuns [...] ela articular-se-ia em torno de representações e rituais que enfatizam a nação como uma comunidade de descendência e como um corpo de natureza étnica, baseado numa língua e em costumes populares idênticos (Leal, 2000; 17).

Apesar de toda a diferença (e rivalidade) existente ainda hoje entre Portugal e Espanha, para Miguel Torga o importante é o passado comum - quando ambos, por exemplo, sofreram invasões de suevos, mouros, visigodos, muçulmanos e por dividirem a mesma nesga de terra, que se assemelha muito mais com as terras ao sul do Mediterrâneo, do que propriamente com os vizinhos de continente.

O indivíduo ou a comunidade que está na busca de uma definição identitária acaba por descobrir duas funções da literatura, de acordo com Edouard Glissant (1981). Uma função dessacralizadora, que desmonta as “engrenagens de um sistema dado" e outra de sacralização, que busca "a união da comunidade em torno de seus mitos, de suas crenças, de seu imaginário ou de sua mitologia”, esta última o caso de Torga.

Publicado em 1965, Poemas Ibéricos é um livro que retrata bem o espírito de nacionalidade de um homem, que pregou - pelo menos nas entrelinhas - o fim das rivalidades ibéricas e um maior diálogo entre os dois países.

Não podemos esquecer a época em que este livro de Miguel Torga foi escrito e lançado - ditaduras portuguesa e espanhola -, ou seja, o poeta queria mostrar que mesmo com 
todas as atrocidades deste tempo, o homem e a terra ibérica são fortes, fecundos e, o mais importante, possuem um passado.

Dividido em quatro partes - História Trágico-Telúrica, História Trágico-Marítima, Os Heróis e O Pesadelo - Poemas Ibéricos busca revisitar a história dos povos da península. Uma versão poetizada por um homem que estava preocupado com esta mesma história e com o que ela possa a vir representar para portugueses e espanhóis

Miguel Torga começa o seu livro com o poema "Ibéria" que, aliás, é independente de quaisquer outras partes do livro, ou seja, o poema em questão é a própria apresentação do livro pelo próprio autor, uma espécie de prefácio ou prólogo.

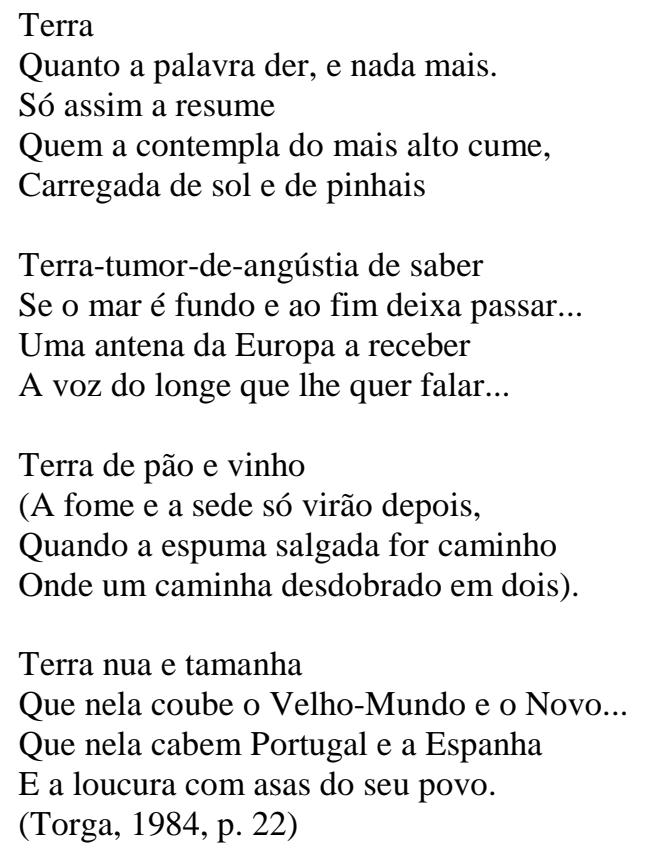

Este poema é, em suma, uma síntese do povo e da terra ibérica. O primeiro quinteto resume como é a península vista dos Pirineus, apenas terra, sol e pinhais - o que nos remete a um ambiente hostil, como um deserto, por exemplo. O primeiro quarteto nos mostra a ânsia de um povo em jogar-se ao mar e enfrentar os seus perigos na procura de novos mundos como diz Torga, este desejo é um tumor (uma coisa enraizada) e uma angústia (grande aflição, uma ansiedade opressora, enfim, agonia). O segundo quarteto mostra as mudanças que o tempo trouxe à Península Ibérica, o fim das riquezas - dos seus dias de potência mundial - e o início de um tempo de maiores privações.

Na parte chamada de História Trágico-Telúrica, Miguel Torga descreve a Península com os seus poemas A Terra, A Raça, Fado, A Vida, O Pão, O Vinho e A Miragem. Ou seja, o poeta trásmontano mostra os elementos básicos que constituem o quinhão ibérico. A primeira estrofe do poema Fado mostra a aceitação do poeta em relação ao destino reservado a 
portugueses e espanhóis, sem a menor intenção de transgredi-lo, uma espécie de aceitação da vontade divina.

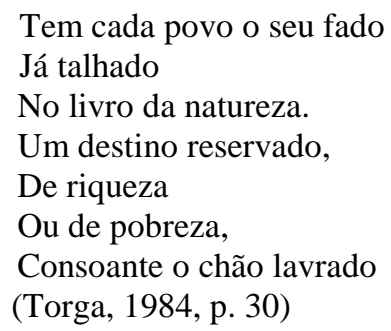

Já no poema $A$ Vida, Torga une os diversos povos da Península em torno de um mesmo povo, que, além do mesmo destino, não deve perder a crença na sua terra, adjetivada pelo mesmo como dura e ruim.

Povo basco, andaluz,

Catalão, português:

O caminho é saibroso e franciscano

Do berço à sepultura;

(Torga, 1984, p. 32)

A segunda parte de Poemas Ibéricos - História Trágico-Marítima - mostra, ou melhor, conta novamente as aventuras do povo ibérico nos tempos das grandes navegações. Sagres faz referência à Escola que tanto contribuiu com avanços científicos à humanidade; $A$ Largada, é um claro diálogo com o episódio do Velho do Restelo de Os Lusíadas. Nesta mesma parte ainda temos ainda os poemas A Espera, O Regresso, O Achado, Tormenta e Mar, que tem no seu último quarteto um certo tom profético e sedutor:

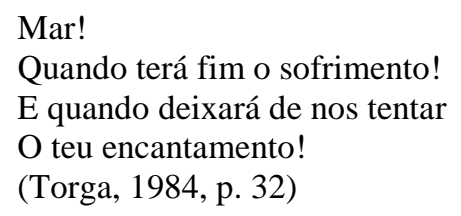

A terceira parte, "Os Heróis", em uma clara referência aos homens do passado. Os heróis de Torga - alguns ainda não tão heróicos - são espanhóis - Cid, Inês de Castro, Torquemada, Herman Cortez, Loiola, Santa Teresa, Filipe II, São João da Cruz, Cervantes, Goya, Unamuno, Picasso, Garcia Lorca -, são portugueses - Nun'Alvares, Infante D. Henrique, D. João II (o Príncipe Perfeito), Bartolomeu Dias, Fernão de Magalhães, Afonso de Albuquerque, Camões, D. Sebastião, Padre Vieira, Herculano e Pessoa - ou são, como Viriato e Séneca, de um tempo onde a península ainda era unificada. Podemos ver então que os heróis desta terra seca, pelo menos para Torga, não são apenas os conquistadores de territórios, riquezas ou que exerceram algum tipo de poder, mas sim aqueles que ajudaram a construir uma cultura e que estiveram na busca de um fortalecimento do espírito nacional. Quase todos artistas que, de uma forma ou outra, serviram como exemplos de uma cultura forte e nada 
como alcançar tal prestígio cultural para que um povo possa ter orgulho de suas raízes e de sua terra.

Chamamos a atenção para alguns versos do poema Unamuno, uma homenagem ao poeta e amigo espanhol que, juntamente com Miguel Torga, via a Península Ibérica como um território só.

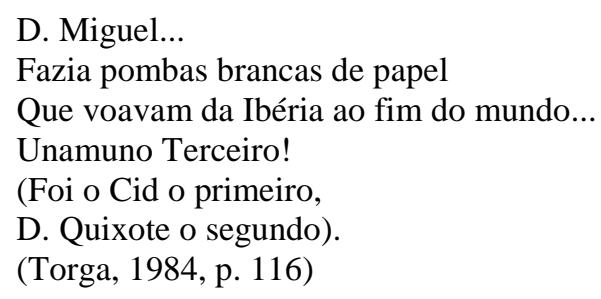

Nesse sexteto o poeta português faz uma referência a outros quixotes que percorreram a península com seus sonhos, Cid, o próprio D. Quixote de la Mancha e Unamuno, agora com o numeral ordinal agregado ao nome, o que lhe dá um caráter de nobre, como D. João II ou Felipe II - também citado no mesmo poema.

Nos seguintes versos, Miguel Torga faz uma referência ao fato de Unamuno ser, assim como ele, um defensor da Ibéria. Inclusive dizendo que somente o poeta espanhol era o protetor destas terras em um momento em que elas estavam abandonadas, ou sendo “dilapidadas por forças desonestas". A pátria para Unamuno é a sua mãe, idéia e namorada, além, é claro, de ser o seu berço de nascimento.

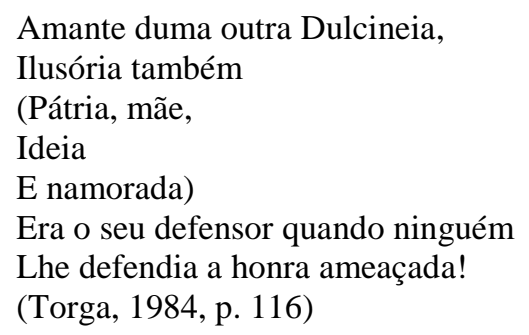

Escrevendo Poemas Ibéricos, Miguel Torga mostra o seu otimismo quanto ao futuro de portugueses e espanhóis, pois um povo que resistiu a aridez do solo, a invasões bárbaras, a regimes autoritários, tem a resistência necessária para continuar a vida em tal terra tendo como aliado a poesia que, segundo Ezra Pound, tem - assim como toda a literatura - a sua função social definida proporcional à qualidade de seus escritores, e um povo que cresceu frente a uma má poesia é um povo que está para perder o pulso do seu país. Uma história que teve Cervantes, Unamuno, Garrett e Pessoa, por exemplo, jamais poderá ser esquecida e enquanto existir Poemas Ibéricos, espanhóis e portugueses poderão encontrar ali o seu passado grandioso e dele tirar as forças necessárias para não perecer defronte às adversidades. 


\section{Referências}

BARZUN, Jacques. Da alvorada à decadência - a história da cultura ocidental de 1500 aos nossos dias. Rio de Janeiro: Campus, 2002.

BERND, Zilá. Literatura e identidade nacional. Porto Alegre: Editora da UFRGS, 2003.

LEAL, João. Etnografias portuguesas (1870 - 1970): cultura popular e identidade nacional. Lisboa: Publicações Dom Quixote, 2000.

MOISÉS, Massaud. A literatura portuguesa. São Paulo: Cultrix, 1960.

RICOEUR, Paul. Temps et récit. Paris: Seuil, 1985 (Tomo 3).

SARAIVA, José Hermano. História concisa de Portugal. Lisboa: Publicações EuropaAmérica, 1983.

SARAMAGO, José. A jangada de pedra. São Paulo: Companhia das Letras, 1988.

TORGA, Miguel. Antologia Poética. Coimbra: Coimbra, 1985.

. Diário V. Coimbra: Coimbra, 1955.

. Poemas Ibéricos. Madrid: Ediciones Cultura Hispanica, 1984. 